\title{
A psicoterapia breve psicanalítica como proposta clínica no núcleo de atendimento e pesquisa da conjugalidade do instituto Sedes Sapientiae
}

\author{
The brief psychoanalytic psychotherapy as proposed by the nucleus of clinical care and research \\ of conjugality at Sedes Sapientae Institute
}

\author{
Márcia R. M. Barone Bartilotti[ ${ }^{[a]}$, Mauro Hegenberg ${ }^{[b]}$, Alice Tamashiro ${ }^{[c]}$, \\ Ana Cláudia D. Modenesi ${ }^{[c]}$, Aparecida Fusaro ${ }^{[c]}$, Juliana Simões ${ }^{[d]}$, Luciane Miranda ${ }^{[c]}$, Mirian Maki ${ }^{[c]}$
}

\footnotetext{
[a] Psicóloga, mestre em Psicologia Clínica, especialista em Psicoterapia Breve Psicanalítica, professora do Curso de Psicoterapia Breve Psicanalítica (Especialização), coordenadora do Núcleo de Atendimento e Pesquisa da Conjugalidade (NAPC) do Instituto Sedes Sapientiae, São Paulo, SP - Brasil, e-mail: marciabbarone@uol.com.br

${ }^{[b]}$ Médico psiquiatra, psicanalista, doutor em Psicologia Clínica, coordenador do Curso de Psicoterapia Breve Psicanalítica (Especialização), supervisor Clínico do Núcleo de Atendimento e Pesquisa da Conjugalidade (NAPC) do Instituto Sedes Sapientiae, São Paulo, SP - Brasil, e-mail: mhegen@uol.com.br

${ }^{[c]}$ Psicólogas, especialistas em Psicoterapia Breve Psicanalítica, terapeutas do Núcleo de Atendimento e Pesquisa da Conjugalidade (NAPC) do Instituto Sedes Sapientiae, São Paulo, SP - Brasil, e-mails: alice_tamashiro@hotmail.com, ana_domingos@strohlbrasil. com.br, aparecidafusaro1@ yahoo.com.br, lucianemogi@ yahoo.com.br, mirian_maki@ ig.com.br
}

\section{Resumo}

Este artigo tem como propósito apresentar os fundamentos teóricos e clínicos que embasam a proposta de psicoterapia breve de orientação psicanalítica no campo da conjugalidade, realizada pelo Núcleo de Atendimento e Pesquisa da Conjugalidade (NAPC) da Clínica Psicológica do Instituto Sedes Sapientiae. A psicoterapia breve de orientação psicanalítica é definida pelo respeito ao vértice psicanalítico, aliado ao limite de tempo previamente estabelecido e à presença de um foco. 0 foco é discriminado a partir das angústias de castração, de fragmentação e de perda de objeto e elucidado nas relações com os tipos de personalidade - obsessivo, narcísico e erótico - definidos por Freud e modificados por Bergeret e Hegenberg. A elucidação e a compreensão dos tipos de personalidade de cada um dos membros do casal e suas respectivas angústias possibilita o esclarecimento das questões que advêm a partir dessas diferenças; diferenças essas geradoras dos conflitos conjugais que mobilizam o casal a buscar ajuda psicoterapêutica. A descrição de um caso clínico ilustra o manejo.

Palavras-chave: Psicoterapia breve psicanalítica. Psicoterapia de casal. Problemas conjugais. Foco. Tipos de personalidade.

\section{Abstract}

The aim of this article is to present the theoretical clinical foundations that give support to the brief psychoanalytic psychotherapy proposal in the conjugality field, as done at the Psychologic Clinic of the Sedes Sapientae Institute by NAPC. The brief psychoanalytic psychotherapy is defined by the respect for the psychoanalytic vertex, allied to the set time limit and the presence of a focus. The focus is broken from the anxieties of castration, of fragmentation and loss of object and elucidated in the relationships with personality types - obsessive, narcissistic and erotic - defined by Freud and modified by Bergeret and Hegenberg. The elucidation and understanding of personality types of each of the spouses and their anxieties enables the clarification of questions arising 
${ }^{[d]}$ Psicóloga, mestre em Psicologia Clínica, especialista em Psicoterapia Breve Psicanalítica, terapeuta do Núcleo de Atendimento e Pesquisa da Conjugalidade (NAPC) do Instituto Sedes Sapientiae, São Paulo, SP - Brasil, e-mail: jusimoes@gmail.com from these differences; these differences give origin to marital conflicts that coerce the couple to seek psychotherapeutic assistance. The discription of a clinical case to illustrate it.

Keywords: Psychoanalytic psychotherapy. Brief psychotherapy. Couple. Marital problems. Focus. Types of personality.

\section{Introdução}

Desde 1999, o curso de Psicoterapia Breve Psicanalítica do Instituto Sedes Sapientiae (ISS) mantém, em sua Clínica Psicológica, atendimento clínico para casais ou indivíduos em situação de conflito conjugal. Esse atendimento se dá no Núcleo de atendimento e pesquisa da conjugalidade (NAPC), formado por antigos alunos do curso de Psicoterapia Breve Psicanalítica do ISS, uma coordenadora e um supervisor.

Os pacientes, constituídos como casais ou não, recorrem ao NAPC no intuito de solucionar problemas do relacionamento a dois; eles vêm à procura de ajuda que lhes permita compreender as razões dos conflitos e problemas, para continuar juntos, a princípio, ou para poderem se separar "civilizadamente".

Nesses mais de dez anos de existência do NAPC, temos observado que a busca pela ajuda psicológica muitas vezes está relacionada a uma problemática que envolve o choque causado pelo confronto entre a realidade da convivência e a idealização da relação conjugal. Homens e mulheres continuam a ter expectativas ilusórias relacionadas a si, ao parceiro e, por consequência, à relação conjugal apaixonada, um dos frutos da tradição ocidental do amor romântico enquanto prerrogativa do casamento, originado no século XVIII durante o período Iluminista.

É interessante notar como, apesar de todo progresso científico, tecnológico e midiático, muitas pessoas ainda procuram a realização do sonho romântico do encontro "da cara metade", que realize todos os seus anseios amorosos e sexuais. Aparentemente, todos parecem estar muito adequados aos princípios da realidade para enfrentar a vida em comum e tudo o que ela significa. Entretanto, não são raras as vezes em que essas idealizações românticas, próprias do início da paixão que permeia o enamoramento, "caem por terra" diante dos problemas do cotidiano.

Nesse cenário, acontecimentos que fazem parte da existência humana, tais como o nascimento de um filho, a perda de poder aquisitivo, a manifestação de uma doença grave na família, a perda de um ente querido, a infidelidade de um dos parceiros, dentre outros acontecimentos, acabam gerando muitas desavenças; consequentemente, os parceiros sentem-se decepcionados, frustrados, traídos e muitas vezes enraivecidos, uma vez que o cônjuge não corresponde às expectativas idealizadas.

Percebe-se ainda grande insatisfação diante de fatos corriqueiros, como diferença de preferências ou hábitos. Preferências pessoais que fazem parte do modo de ser de cada um parecem ser inadmissíveis em determinados casais, tudo tendo que ser exatamente o mesmo para os dois, como se fosse um a extensão do outro. Há muita confusão sobre o significado de união e simbiose.

Contudo, temos observado em nossa prática clínica que um importante fator que compreende as queixas, insatisfações e conflitos constantes diz respeito às diferenças inerentes à personalidade de cada um. Casais de várias faixas etárias e diferentes níveis socioculturais ou econômicos têm procurado o núcleo; quando não estão em crise pessoal severa, em que perderam o próprio sentido da existência, o que se tem observado são problemas relacionados com a falta de compreensão sobre as características de personalidade do outro. Alguém ser mais ou menos introspectivo, mais ou menos sociável, mais ou menos interessado pelo próprio trabalho, ter maior ou menor interesse em estar junto das famílias de origem, ser mais determinado em conseguir seus objetivos, 
batalhar mais ou menos pelos próprios interesses ou mesmo parecer "desligado" são condições geradoras de conflitos. Lidar com as diferenças torna-se muito difícil, quase impossível. É frequente nos depararmos com casais em que um quer que o outro "mude" para que o relacionamento possa dar certo.

Num certo momento, a relação torna-se tão impregnada de incompreensão, os desentendimentos atingem tal ordem que o amor e o sexo parecem não mais ter lugar para existir. A distância entre os parceiros aumenta, um ciclo vicioso se forma, tornando o dia a dia insuportável (ou quase) e, consequentemente, o casal "entra em crise" e procura psicoterapia.

Tendo em vista essas questões, nosso enfoque clínico tem como eixo central esclarecer as interações conflitivas entre os membros do casal, elucidar suas angústias e seu modo de funcionamento psíquico recíproco a partir da compreensão dos tipos de personalidade de cada um, conforme proposta de Hegenberg (2004/2010). Tal proposta foi estabelecida pelo autor com base na compreensão dos tipos de personalidade obsessivo, narcísico e erótico, descritos por Freud em 1931 no artigo denominado "Tipos Libidinais" (Freud, 2000), bem como nas contribuições de Jean Bergeret, mencionadas em seu livro Personalidade normal e patológica (Bergeret, 1974).

Em muitos casos, durante o processo de psicoterapia breve psicanalítica que é oferecido, aparecem também questões pessoais mal resolvidas sobre as quais a própria pessoa não tem suficiente clareza e que contribuem para o surgimento das dificuldades conjugais. Em geral, nessas situações, é proposto um trabalho na modalidade individual como um complemento à terapia de casal.

Este artigo apresenta a linha teórica do trabalho oferecido pelo NAPC, ilustrada pelo atendimento de um caso.

\section{Modelo Teórico-Clínico}

O NAPC segue o modelo teórico de "psicoterapia breve de orientação psicanalítica" desenvolvido por Hegenberg (2004), ou seja, adota um vértice psicanalítico compreendido pela articulação entre a teoria e um procedimento determinado: a investigação/análise da transferência, a interpretação, a utilização das associações livres e o respeito à neutralidade. A terapia breve de casal pode durar de algumas sessões até um ano.

0 nome "psicoterapia breve" (PB) é inadequado porque não é o tempo breve que a define, mas sim o limite de tempo de atendimento tendo em vista um foco determinado. Para uma psicoterapia psicanalítica ser considerada breve, dois elementos constitutivos e fundamentais se agregam: o limite de tempo previamente estabelecido e a presença de um foco (Hegenberg, 2004).

\section{Limite de tempo}

Seguimos a proposta defendida por Malan, desde a década de 1960, a partir de pesquisas de Balint desenvolvidas na Tavistok Clinic, em relação ao limite de tempo, que, se previamente definido e acordado pelo terapeuta e pelo casal, dá contornos à relação terapêutica.

Essa linha de pensamento também encontra apoio dos estudos de Gilliéron. Em seu livro acerca das contribuições psicanalíticas para a psicoterapia breve, Gilléron desenvolve a ideia de que o limite de tempo preestabelecido modifica a relação com o paciente ao introduzir a noção de castração. De acordo com as colocações do autor, em face da limitação temporal, as satisfações regressivas são inibidas, o benefício secundário dos sintomas é alterado e a compulsão à repetição se modifica, permitindo, assim, o trabalho com as associações livres sem necessidade de focalização ativa por parte do terapeuta.

Ao lado dessas observações, Gilliéron ainda assinala que não é necessário evitar a neurose de transferência uma vez que ela deixa de ser estimulada em função do contexto instituído pela castração a partir do limite de tempo preestabelecido. A limitação do tempo, como elemento determinante do contrato de terapia, torna-se suporte do processo transferencial, além de fornecer um eixo para o trabalho de elaboração e de perlaboração (Gilliéron, 1983).

\section{Focalização}

O estabelecimento do foco é fundamental. Em nosso trabalho, como também assinalado por Hegenberg (2010), o foco será a explicitação do entrelaçamento das angústias de cada membro do casal e sua repercussão no modo de funcionamento psíquico da díade. 
As angústias de castração, de fragmentação e de perda do objeto são esclarecidas a partir da compreensão dos tipos de personalidade de cada um, compreendidos a partir das repetições das relações primitivas que interferem nas questões atuais e explicitadas nas sessões, em função da experiência intersubjetiva do casal uma vez que acabam surgindo também na relação com o terapeuta.

As questões transferenciais do casal e de cada membro com o terapeuta e as colaterais entre eles, atravessadas pelas projeções mútuas das imagos primitivas, permeiam a atenção do terapeuta no manejo do foco nas sessões, compreendidas, também, por meio da contratransferência.

\section{Tipos de personalidade}

No texto "Tipos libidinais", de 1931, Freud considera a existência de três tipos psicológicos classificados com base na situação libidinal e os denomina como tipo erótico, tipo narcísico e tipo obsessivo. Nesse texto, o autor também explicita as características de cada tipo.

Assim, de acordo com Freud (1931), o tipo erótico está voltado para o amor. "Amar, mas acima de tudo ser amado". São pessoas "dominadas pelo temor da perda do amor e acham-se, portanto, especialmente dependentes de outros que podem retirar seu amor deles". Algumas "variantes ocorrem segundo se ache mesclado com outro tipo, e proporcionalmente à quantidade de agressividade nele presente" (Freud, 1931, p. 252).

O tipo obsessivo caracteriza-se pela predominância do superego. São indivíduos dominados pelo temor de sua consciência em vez do medo de perder o amor e com alto grau de autoconfiança (Freud, 1931, p. 252). Em $O$ mal-estar na civilização, Freud também faz considerações a esse respeito e refere-se ao tipo obsessivo como pessoa de ação, que "nunca abandonará o mundo externo, onde pode testar sua força" (Freud, 1929, p. 103).

0 terceiro tipo, denominado tipo narcísico, é independente e não se abre à intimidação. Não existe conflito entre o ego e o superego e o interesse central do indivíduo aponta para a autopreservação. Seu ego possui uma grande quantidade de agressividade à sua disposição, a qual se manifesta na presteza à atividade. 0 amar é preferido ao ser amado. "Podem assumir o papel de líderes, não se incomodam em danificar o estado de coisas estabelecido" (Freud, $1931 / 2000$, p. 252, 253). Tende a ser autossuficiente, buscará suas satisfações principais em seus processos mentais internos (Freud, 1929, p. 103).

Os tipos obsessivo, narcísico e erótico correspondem respectivamente, com ressalvas, aos tipos Neurótico (N), Psicótico (P) e Estado Limite (EL), propostos por Hegenberg (2004) a partir das contribuições de Bergeret (1974) acerca dos critérios de classificação de duas estruturas de personalidade (neurótica e psicótica) e de uma organização (estado-limite).

Cabe ressaltar que Freud nos aponta, com razão, que os tipos puros são teóricos e que os tipos mistos são os clinicamente observáveis "a partir da experiência”" (Freud, 1931/2000, p. 253). Em outras palavras, os tipos mistos teriam características de mais do que um dos tipos retratados por Freud. Essa perspectiva nos faz pensar que o tipo EL/P, por exemplo, teria características do tipo EL e do tipo P, compondo um tipo psicológico com características próprias, em decorrência da biografia de cada um.

Freud (1931/2000) ainda nos alerta que esses tipos psicológicos não coincidem com quadros clínicos, mas ajudam a unir o abismo entre o normal e o patológico. Seguindo esse raciocínio, Bergeret (1974) também assinala que dentro das estruturas, passa-se da normalidade à patologia, com variações de grau, mas ressalta que a organização estado-limite não comporta este estatuto de normalidade.

A proposta de Hegenberg (2004) vem nos ajudar, uma vez que destaca a possibilidade de estados-limites normais, ou seja, com quadros não severos. Assim, a proposta do autor considera as contribuições de Bergeret, porém não entra na discussão da noção de estrutura e organização, optando por pensar em tipos de personalidade.

Nesse contexto, Hegenberg (2004) compreende que há o tipo neurótico normal e o patológico, assim como o tipo psicótico normal e o patológico e o tipo estado-limite normal e o patológico. Por essa razão, considera que não há um tipo mais evoluído ou mais saudável do que o outro; os três tipos têm suas vantagens e suas desvantagens, os três beneficiam-se e sofrem com seu modo de ser.

\section{Sobre os tipos de personalidade P, N e EL}

Como descrito por Hegenberg (2004), o tipo $\mathrm{N}$ tem no superego sua instância dominante, sua 
angústia principal é de castração, o conflito é entre o superego e o id, a defesa é de recalcamento e a relação de objeto é genital, ou edípica. É o neurótico de Bergeret (1974), é a pessoa total a que se refere Winnicott (1954/1955), em artigo no qual apresenta uma conceituação condizente com os tipos aqui descritos. São pessoas caracterizadas pela ambição e pela competitividade, com bom controle dos impulsos, superego severo com defesas obsessivas, relações de objeto triangulares, exibicionismo sexualizado ou mais ligados à ordem e parcimônia, obstinados, insatisfeitos, individualistas, austeros, racionais e lógicos, teimosos, submetidos a um superego punitivo. Na prática clínica, são pacientes que despertam no terapeuta a vontade de competir na relação transferencial ou a sensação de ser questionado, incompetente, castrado.

Os aspectos neuróticos levam a pessoa à ação, à conquista, à busca pelo poder, à disputa. A pessoa pode ser falante, às vezes agressiva, incisiva, acusadora, pode parecer autoritária. Seu modo de se colocar no mundo sugere alguém empreendedor, agressivo nos negócios, aparentemente interessado em poder, dinheiro. Ao lidar com a castração, o neurótico deseja o triunfo fálico e a disputa torna-se imperativa. Competir passa a ser mais interessante que escutar ou compartilhar, embora a culpa pela conquista possa atrapalhar. A focalização, nesses casos, passará pelas questões ligadas à castração. Os casos graves desse tipo são a histeria e o transtorno obsessivo-compulsivo.

0 tipo $\mathrm{P}$ tem no id sua instância dominante, sua angústia principal é de fragmentação, a relação de objeto é fusional, o conflito é entre o id e a realidade, e as defesas principais são a recusa da realidade, a projeção e a clivagem do ego. É o psicótico de Bergeret (1974), que admite uma pessoa normal transitando pelos mesmos caminhos que o psicótico doente.

Bergeret (1974) critica os aristocratas do Édipo, alertando que a personalidade não precisa se estruturar na passagem pela triangularidade para ser considerada normal. São pessoas com comportamentos permeados pela questão da organização/ desorganização, são profundas, mais próximas do id, centradas nelas mesmas, estabelecendo delicada relação com o ambiente potencialmente desestruturador. Alguns são confusos, às vezes são desconfiados, outros são obsessivamente rígidos para evitar a desorganização. Em geral, têm um mundo interno rico, são criativos, com ideias próprias, porque a instância dominante é o id. Para se defenderem de uma opinião potencialmente invasiva e desorganizadora, podem parecer teimosos. Como a relação de objeto é fusional, defendem-se da proximidade excessiva, que pode ser fator de desorganização interna. 0 terapeuta, diante desses pacientes, tende a organizá-los. Os casos graves desse tipo são a esquizofrenia, a paranoia e a melancolia.

O tipo EL tem como instância dominante o ideal do ego, a angústia principal é de perda do objeto, a relação de objeto é de apoio ou anaclítica, a defesa principal é a clivagem dos objetos em bom e mau, o conflito é entre o ideal do ego e o id e a realidade. Há conquista superegoica e edípica, mas eles não são os organizadores da personalidade. Nessas pessoas, a relação é de dependência com o objeto de apoio, fruto do ideal do ego que predomina. 0 sujeito se defende da depressão, que não é melancólica e que aparece quando o objeto anaclítico deixa de apoiar. São questões frequentes o conflito com o outro a partir da ambiguidade instalada com a equação dependência/independência. Na relação transferencial, o terapeuta tende a confortar, a apoiar. São os chamados estados-limite, e seus casos graves são o borderline, a personalidade antissocial e as perversões.

Os tipos EL e P não têm o Édipo como principal instância organizadora, o que não quer dizer que não sejam influenciados por ele. A diferença é que no tipo N, o Édipo é central e a castração é a angústia básica de sua personalidade, enquanto no estado-limite e no psicótico, normais ou não, o Édipo influencia, mas as angústias básicas são a de perda do objeto e a de fragmentação, respectivamente.

Embora esses conceitos tenham como finalidade a aproximação clínica com o paciente, se faz necessário evitar qualquer visão reducionista. Todas as pessoas são criativas em maior ou menor grau, todos se defendem de invasões, todos lidam com a castração, todos têm que lidar com a angústia de perda do objeto e de fragmentação, todos têm as características apontadas em cada um dos três tipos. Porém, é perceptível, que algumas dessas características predominam em uma ou outra pessoa.

Essas características de personalidade são naturalmente investigadas, pouco a pouco, ao longo de uma psicoterapia sem prazo fixo, em todos os pacientes. Em uma PB, reconhecê-las e apontá-las, no momento dado pela procura de terapia, propicia insight e autoconhecimento, facilitando a compreensão da situação conflitiva que o paciente apresenta. 
Na psicoterapia de casal, como salientado por Hegenberg (2010), o foco proposto se dará nas observações clínicas, realizadas a partir do entrecruzamento das características de personalidade com as dificuldades e angústias que permeiam a vida em comum, propiciando ao casal uma melhor compreensão de como se relacionam.

Em outras palavras, ao longo do processo terapêutico, o terapeuta procurará demonstrar, com exemplos extraídos da vida cotidiana, como as angústias de fragmentação, de castração e de perda do objeto influenciam as respostas emocionais de ambos os cônjuges, auxiliando o casal a compreender e a obter uma nova leitura de seus conflitos costumeiros, além de propiciar insight e autoconhecimento (Hegenberg, 2010).

Aliado ao modelo teórico de psicoterapia breve de orientação psicanalítica, o percurso da escolha dos conceitos também privilegia os tipos de organização do casal delineados por Eiguer (1991). Segundo o autor, os casais podem ser organizados em três tipos: neuróticos (ou normais), anaclíticos (ou com angústia de perda, ou depressivos) e narcísicos (ou psicóticos). Os casais neuróticos são organizados pelo Édipo, os anaclíticos por apoio e os psicóticos por simetria ou narcisicamente.

Em sua concepção, os casais neuróticos apresentam conflitos relacionados à vida sexual (impotência, ejaculação precoce, vaginismo, anorgasmia), questões extraconjugais, além de rivalidade profissional e sentimento de inveja.

Diferentemente dos casais neuróticos, os casais anaclíticos apresentam como questão central dificuldades no estabelecimento de um vínculo de confiança entre eles, além de questões que envolvem família, filhos, amigos. Ou seja, os outros, em geral, invadem o discurso do casal, o que pode ser compreendido, segundo Eiguer, como uma defesa, uma maneira de atenuar ou afastar a possibilidade de perda e, consequentemente, de apoio. São muito sensíveis a mudanças e a nostalgia é uma característica significativa.

No que se refere aos casais narcísicos (ou psicóticos), os problemas relacionados ao poder, à dominação e ao controle são centrais; aspiram à fusão. A presença de ressentimentos e a recusa do sexo por desinteresse também são aspectos que caracterizam o casal organizado de modo narcísico.

Cabe ressaltar que essa proposta de trabalho clínico está associada, obrigatoriamente, à compreensão das histórias de vida, às projeções e introjeções vividas pelas experiências e às relações objetais primitivas, bem como à relação terapêutica.

A preocupação com a demanda, a renúncia da ação sobre o real e sobre a vontade de suprimir o sintoma ao buscar seu sentido (Lemaire, 1998) também são conceitos psicanalíticos considerados em nosso modelo teórico-clínico.

\section{Material clínico}

Sílvia e Ricardo ${ }^{1}$ procuraram atendimento na Clínica Psicológica do ISS após indicação realizada pela terapeuta de uma das filhas do casal. A iniciativa para o agendamento da primeira consulta foi dele.

O casal compareceu para a recepção dos pacientes $^{2}$ no horário combinado.

Ela, 47 anos, um pouco acima do peso para sua estatura, chamava atenção pelo seu jeito entristecido, seus ombros "caídos", o cabelo curto e pouco cuidado. Suas roupas, em geral, pretas, escondiam qualquer marca de feminilidade. Ele, 50 anos, mais comunicativo e próximo, mais amável e solícito. No sentido inverso, chamava atenção sua maneira de se vestir. Sempre de terno, de suspensórios, com gravatas coloridas ou de estampas infantis. Duas filhas, de 11 e 7 anos, completam a família.

0 cumprimento inicial foi amistoso, porém mais caloroso da parte dele e mais distante da parte dela. Na sala de atendimento, olharam ao redor na tentativa de se localizarem e escolheram as poltronas destinadas aos pacientes somente após a terapeuta ocupar a sua. Em seguida, ele começou o relato dizendo que ambos estavam ali porque tinham muita dificuldade para lidar com as filhas e desejavam orientações de como deveriam agir. Não sabiam mais o que fazer em relação ao comportamento e atitude das filhas, pois elas faziam "muita bagunça, muito barulho, brigavam entre si e tumultuavam o ambiente". Como a família morava "de favor" na casa dos pais de Sílvia, os quais já eram idosos, ambos tinham que, quase

\footnotetext{
1 Os nomes são fictícios e os dados objetivos foram alterados para preservar o anonimato dos sujeitos.

2 A recepção dos pacientes no NAPC funciona em regime semanal de plantão na Clínica do ISS.
} 
continuadamente, chamar a atenção das filhas, o que gerava muitas discussões e desgaste entre todos e entre o casal. Enquanto ele falava, ela permanecia calada, mas lançava olhares à terapeuta e suas expressões sugeriam discordância com o que ele relatava.

A terapeuta acolheu esse pedido de orientação, fez algumas intervenções e, num segundo momento, após pontuar que eles haviam procurado um atendimento de casal, foi que ambos relataram a queixa de muitas dificuldades no relacionamento, agravadas pela vivência de um período de crise, em que predominavam muita intolerância, incompreensão, insatisfação e descontentamento.

Ricardo se queixou de que Sílvia é muito resistente a mudanças, tem sempre uma opinião formada sobre tudo e acha que está sempre certa. Reconhece que ela se esforça para dar conta da casa, do trabalho e das filhas, mas sente muita falta do jeito "animado e brincalhão" que ela tinha quando se conheceram, de suas gargalhadas e da maneira carinhosa como ela o tratava ou se dirigia a ele. Ressaltou que ela, muitas vezes, se retrai, pouco conversa quando ele chega em casa cansado após mais um dia de entrevistas (ele estava desempregado).

Ela alegou que precisa ficar quieta, ver a novela e não pensar em nada, para relaxar um pouco da rotina diária com as filhas e afazeres domésticos. Queixou-se de que ele cobra atenção e que sempre quer mais do que ela pode oferecer. Reconhecia que ele cuida bem das filhas, que é bom pai, mas que acreditava que eles estavam nessa situação complicada por culpa dele. Não concorda com sua maneira de pensar - "que é apenas uma fase ruim e transitória e que o importante é ter pensamento positivo".

Ele reagiu e alegou que ela o culpa pela situação, mas que nada faz de concreto. Verbalizou que até a busca pela ajuda psicológica só tinha acontecido por iniciativa dele. Nesse momento, ela ficou bastante tocada ao reconhecer a sua própria "paralisia" diante da situação e, num tom ressentido, relatou que sentia muita falta das atividades de lazer que o casal tinha. Atualmente, a única coisa que fazia, muito raramente, era passar uma tarde com algumas amigas. Com a chegada das filhas, também não conseguiu manter suas atividades profissionais (era representante de uma linha de cosméticos). Nem mesmo morando com os pais ela conseguia "dar conta de tudo".

No decorrer do atendimento, o casal também se queixou do distanciamento sexual instalado entre eles. Segundo Ricardo, desde o nascimento da segunda filha, a vida sexual do casal praticamente não existia mais, pois Sílvia teme engravidar novamente. Quando questionados sobre métodos contraceptivos, ela disse, num tom acusatório, que Ricardo "não cumpriu o combinado", referindo-se à vasectomia.

Na opinião dos dois, o casamento havia se tornado "algo quase que insuportável". Tinham poucas esperanças quanto à possibilidade de estruturarem novas formas de convivência, mas a perspectiva de uma separação era algo que os afligia muito. Nas sessões, quando se aproximavam dessa temática, sempre traziam dificuldades de ordem prática e, particularmente, financeira, permanecendo juntos em um estado de paralisia.

Casados há 13 anos, Sílvia e Ricardo gozavam de estabilidade financeira no início do relacionamento. Os dois terminaram o ensino médio e não têm curso superior. Ele trabalhou com o pai em diversos ramos de atividades e sempre teve boa remuneração. Ela, desde os dezesseis anos era vendedora autônoma (cosméticos femininos), trabalho que lhe proporcionava bom retorno financeiro, além da liberdade de horário.

Conheceram-se em uma casa noturna no litoral paulista, pois ambos gostavam muito de sair. Até o nascimento da primeira filha, costumavam sair e viajar com frequência. Porém, no final da primeira gestação de Sílvia (após dois anos de casamento), as coisas mudaram: além da chegada do bebê, o pai de Ricardo teve muitos problemas financeiros com o último empreendimento e, em razão da falência, Ricardo ficou sem emprego e o casal precisou ir morar com os pais dela.

O que era para ser transitório acabou durando oito anos, pois, embora trabalhando como gerente em casas noturnas, Ricardo não tinha um salário compatível com as necessidades da família, nem estabilidade no emprego. Após esse período, e já com a segunda filha, ele conseguiu uma colocação como gerente de uma rede de supermercados, e o casal resolveu comprar um imóvel financiado. Moraram no local por apenas três anos, pois ele foi demitido, as dívidas se acumularam, perderam o imóvel e precisaram voltar a morar na casa dos pais de Sílvia.

\section{Manejo clínico do caso}

No processo de psicoterapia breve desse casal, existiu, desde o início, uma preocupação com a 
elucidação do modo de funcionamento psíquico a partir da compreensão dos tipos de personalidade. Nesse contexto, as observações clínicas da terapeuta procuraram explicitar as razões pelas quais um e outro se comportavam de maneira tão distinta, visando oferecer ao casal um novo enfoque para suas divergências e, consequentemente, abrir espaço para novas dinâmicas conjugais.

Ricardo se queixa porque Sílvia é resistente a mudanças, não abre mão do que pensa e também porque ela, muitas vezes, se retrai e pouca atenção lhe dá. Ele entende tais comportamentos como teimosia, "birra" e indiferença. Fica irritado e magoado com ela, além de cobrar-lhe mais atenção.

Após a terapeuta salientar ao casal as características P de Sílvia, eles puderam entrar em contato com uma nova perspectiva de compreender a situação.

Como a natureza da angústia do tipo P é de fragmentação e a relação de objeto é fusional, a pessoa procura tanto se defender de invasões potencialmente desorganizadoras quanto manter certa distância afetiva do outro para não se desorganizar. Para que Ricardo possa compreender melhor sua esposa, é interessante que ele saiba que ela estabelece uma relação delicada com o ambiente; isso porque esse ambiente pode ser um fator de desorganização pessoal, e que ela se esforça psicologicamente para que isso não aconteça. Dito dessa forma, pode parecer teórico demais; porém, no momento em que é pontuada a necessidade de Sílvia de se manter em silêncio ou ficar um pouco "em seu mundo", mais absorta e distante, esses comportamentos passam a ser melhor compreendidos por Ricardo. 0 fato de ela precisar de repouso e de pouco estímulo passa a ser entendido não como descaso ou indiferença, mas sim como necessidade.

A compreensão dos tipos de personalidade é mais bem entendida quando associada à biografia. Sílvia é a filha mais nova. Tem uma irmã dois anos mais velha. A família é natural de São Paulo, mas residiram em diferentes cidades e países em virtude da atividade profissional do pai, que era jogador de basquete. Da infância à adolescência, Sílvia mudou-se várias vezes. A mãe sempre foi dona casa e, segundo Sílvia, "mais esposa do que mãe". Cuidava dos filhos de maneira distante, com poucas palavras, pouco contato físico e sem demonstrações de afetividade. 0 pai era mais próximo, "mais caloroso". Tinha o costume, em suas folgas, de levar os filhos para brincarem juntos nas piscinas dos clubes onde jogava. Contudo, quando o programa envolvia também a esposa, ele "dava preferência" a ela. Os pais também mantinham uma vida social intensa, "gostavam de curtir a vida", sempre que possível. Como residiam distante dos familiares, em geral os filhos os acompanhavam nos eventos, mas com a condição de "não atrapalharem".

No caso de Sílvia, seu tipo de personalidade P foi acentuado pelo estilo de vida em família que a estimulava a se virar sozinha. Para sua própria sobrevivência psíquica, ela aprendeu a contar com ela mesma. Fazer tal relação possibilitou ao casal uma melhor compreensão do tipo de personalidade e do funcionamento psíquico dela.

Quanto a Ricardo, pode-se dizer algo semelhante em relação ao seu tipo de personalidade EL. Para ele, Sílvia não o ama o suficiente, nem o valoriza. Suas queixas são direcionadas para obter mais carinho e atenção. Quando ela no final do dia prefere "ver a novela" em vez de estar com ele, a mensagem é que ela não lhe dá valor, que pouco se importa com ele.

Como a natureza da angústia do tipo EL é de perda e a relação de objeto é anaclítica, ou seja, de apoio, há necessidade de afeto, de apoio e de compreensão. Os indivíduos EL fogem da solidão e a ameaça de abandono é vivenciada com muito sofrimento. Em virtude desses aspectos, tornam-se dependentes e, não raras vezes, solicitantes de cuidado. Assim, para Sílvia compreender melhor Ricardo, é importante que ela se dê conta de que as queixas e solicitações dele não são caprichos, mas carências fundadas nas suas relações primitivas. Suas exigências de cuidado fazem parte da necessidade de uma relação de apoio. À medida que Sílvia conheceu o funcionamento EL de seu marido, essa justificativa tornou-se plausível. Antes disso, sua única explicação era a cobrança e a exigência excessiva, com as consequentes desavenças.

A circunstância biográfica que justifica o tipo de personalidade EL de Ricardo também está associada ao estilo de vida de sua família de origem. Sua relação com os pais "sempre foi complicada", permeada por brigas e discussões constantes entre os pais, principalmente, pelas queixas de seu pai por causa da falta de cuidado de sua mãe em relação aos filhos. Ele é o filho mais velho, tem dois irmãos do primeiro casamento do pai e uma irmã adolescente do segundo casamento. Seus pais se separaram quando ele tinha 18 anos, e a 
separação foi "muito tumultuada e traumática", por causa de vários episódios de traição por parte de sua mãe; situação que ela "não escondia de ninguém, nem mesmo dos filhos". Com a separação, os filhos ficaram morando com o pai; Ricardo; além de residir com o pai até seu casamento com Sílvia, sempre trabalhou com ele. 0 início de sua vida profissional fora da estrutura familiar coincidiu com o início de seus problemas financeiros e a consequente necessidade do apoio da família de Sílvia, o que sugere uma relação de dependência com o pai não apenas de ordem financeira.

Importante ressaltar que, obviamente, cada um tem o direito de escolher com quem vive. 0 fato de conhecer seu marido não significa que Sílvia tenha de aceitá-lo como ele é e vice-versa. Entretanto, o conhecimento dos tipos de personalidade facilita decisões sobre separação ou continuidade do relacionamento, inclusive porque salienta os limites de cada pessoa. Dificilmente Sílvia poderia se tornar a esposa cheia de cuidados de que Ricardo precisa para se sentir amado. Por outro lado, ela pode tentar fazê-lo, uma vez que conheça o que o marido necessita e o porquê disso.

Outro aspecto relevante se refere ao fato de que, embora as pessoas tenham como base um tipo específico de personalidade, todas têm características dos três tipos aqui descritos. São os chamados tipos mistos de Freud. No casal exemplificado, pode-se dizer que Sílvia tem características do tipo EL. Suas questões também incluem uma dificuldade em abrir mão da condição de filha - onde o sustento e o prazer eram providenciados pelo pai - e ocupar o lugar de mãe e mulher. Já Ricardo, tem características do tipo P de personalidade. Em sua fala para a esposa "você precisa ter pensamento positivo para que a mudança ocorra", acreditando que estão vivendo uma fase transitória ao longo de tantos anos, apresenta aspectos que também sinalizam um conflito com a realidade.

No que diz respeito ao tipo de organização do casal, pode-se dizer que o casal exemplificado funciona de modo anaclítico. A relação serve, a ambos, como apoio, atenuando o sofrimento ora de um, ora de outro, já que, apesar das queixas, possibilita a ideia e ou a sensação de acompanhamento mútuo. "Juntos, somos fortes".

Essas observações foram feitas ao longo da terapia, nas ocasiões que pareceram mais adequadas. No exemplo clínico citado, o processo de psicoterapia breve foi realizado em 18 sessões, durante cinco meses.

\section{Considerações finais}

Há diferentes possibilidades de caminho a seguir em uma terapia de casal. Em nossa proposta, optamos por apresentar e discutir as interações entre o casal, suas angústias - atravessadas pelas histórias de vida e relações primitivas - bem como delinear a importância dessas questões no desencadeamento de conflitos e desencontros que mobilizaram a busca pela ajuda psicológica.

Obviamente, questões pessoais podem ser aprofundadas. Entretanto, a proposta de trabalho utilizada pelo NAPC parte do princípio de que não faz sentido realizar psicoterapias individuais em um atendimento de casal. Assim, se um ou os dois membros do casal apresentam tal demanda, nos parece mais adequado realizar um encaminhamento para um trabalho individual, o que não ocorreu no caso aqui citado.

\section{Referências}

Bergeret, J. (1974). La personnalité normale et pathologique. Paris: Dunod.

Eiguer, A. (1991). La thérapie psychanalitique du couple. Paris: Dunod.

Freud, S. (2000). Mal estar na civilização. (Vol. 21, p. 103). Rio de Janeiro: Imago. (Obras Completas de Sigmund Freud).

Freud, S. (2000). Tipos libidinais. (Vol. 21, p. 248). Rio de Janeiro: Imago. (Obras Completas de Sigmund Freud).

Gillieron, E. (1986). As psicoterapias breves. Rio de Janeiro: Jorge Zahar.

Hegenberg, M. (2004). Psicoterapia Breve. São Paulo: Casa do Psicólogo.

Hegenberg, M. (In press). Types psychologiques em thérapie du couple. Revue Internationale de Psychanalyse de Couple et de la Famille.

Lemaire, J. (1974). Terapias de pareja. Buenos Aires: Amorrotu.

Winnicott, D. (1988). Da terapia à psicanálise. Rio de Janeiro: Francisco Alves. 